\title{
Temperature, Snowmelt, and the Onset of Spring Season Landslides in the Central Rocky Mountains
}

Open-File Report 1997-027 


\section{U.S. DEPARTMENT OF THE INTERIOR \\ U.S. GEOLOGICAL SURVEY}

\section{Temperature, Snowmelt, and the Onset of Spring Season Landslides in the Central Rocky Mountains}

by

Alan F. Chleborad1

Open-File Report 97-27

This report has not been reviewed for conformity with U.S. Geological Survey editorial standards and stratigraphic nomenclature. Any use of trade or company names is for descriptive purposes only and does not imply endorsement by the U.S. Geological Survey.

1Denver, Colorado

\section{ABSTRACT}

Snow meltwater (snowmelt) that seeps into the subsurface is a major factor contributing to the development of landslides during the spring in mountainous areas of the Rocky Mountain region. An examination of historical temperature data in relation to spring season landslide occurrences reveals an association between the landslide events and intervals of rising temperatures that accelerate the production of snow meltwater. Historical climatic data recorded at local weather stations located near the landslide sites are used to show the association and to identify a temperature threshold that may be useful for forecasting the onset of spring season landslides. Historical daily temperature maximums and minimums for unmonitored landslide sites are estimated by applying an elevation correction factor to historical temperature data from nearby weather stations. The proposed temperature 
threshold (a 6-day moving average of daily maximum temperature of $58^{\circ} \mathrm{F}$ ) is defined by the number and temporal distribution of snowmelt related landslide events. The results of the study suggest that real-time temperature data recorded at weather stations throughout the Rocky Mountain region is potentially a valuable source of information that may be useful for forecasting the onset of spring season landslides.

\section{INTRODUCTION}

Landslides triggered by snowmelt or a combination of snowmelt and rainfall are common during the spring in many mountainous areas of the Rocky Mountain region. Spring season landslides, especially debris flows (often referred to as "mudslides" in media news reports), are numerous in years with unusually heavy snowfall and associated deep snowpack. However, few details are known of the sequence, time, intensity, or duration of antecedent climatic conditions that trigger the slope failures. Such information may be useful for mitigation of landslide hazards and for forecasting the occurrence of landslides.

For many years, climatic data, including daily temperature maximum and minimums and precipitation, have been collected at numerous local weather stations (weather observing sites) supervised by the National Oceanic and Atmospheric Administration (NOAA)/National Weather Service. I undertook this study to investigate the usefulness of this source of historical climatic data for identifying associations between antecedent climatic conditions and the onset of spring season landslides in mountainous areas of Colorado and other states in the Rocky Mountain region.

\section{METHODOLOGY AND DATA COMPILATION}

For this preliminary report, I have compiled information on 20 landslide events (associated with 18 landslides in the state of Colorado and one in Wyoming) that occurred during the spring in 
years between 1977 and 1996 . Landslide information was gathered from historical newspaper accounts provided by the Colorado Historical Society, technical reports, and from my recent personal field notes. February thru June issues of local newspapers were searched to obtain information on the earliest reported spring season landslide occurrences. The reports were found in April, May, and June issues of newspapers published in the Colorado mountain communities of Aspen, Dillon, Cortez, Steamboat Springs, Montrose, and Telluride. A reported landslide event was included in this study if it met the following criteria: (1) verifiable information on the location and date of occurrence was provided, (2) pertinent historical climate data from a nearby weather station, including daily temperature maximums and minimums, was available, and (3) based on available reports and climatic data, snowmelt appeared to be a major factor contributing to the occurrence of the landslide event.

Information obtained in the search on individual landslide events, including brief descriptions, dates of occurrence, and sources of information, is presented in Table 1. Locations of the landslides are shown in Figure 1. During the fall of 1996, I visited the landslide sites, plotted their locations on topographic maps, and determined elevations. In this preliminary study, no effort was made to further determine details of the reported slope failures other than to verify the locations, elevations, and times of occurrence.

In most cases, relatively small movements of a landslide mass, often indicated by the development of ground cracks or other surface manifestations, precede complete or catastrophic failure. For the purpose of this report, the date of landslide occurrence is defined as the date of complete or catastrophic failure as indicated by large amounts of movement or total disruption of the landslide mass. An exception to this are dates I have included for initial, spring season movements of a pre-existing landslide in Wyoming 
(landslide events No.1 and 2 in Table 1) that were detected using borehole instrumentation (Chleborad, 1980).

For each of the landslide events listed in Table 1, I compiled historical daily precipitation and temperature data recorded at a local weather station. Factors that affect the representativeness of the data, such as topographic variations, were considered in the selection process. In most cases, data from the weather station closest to the landslide was selected as most representative. Locations, elevations, distances between weather stations and respective landslides, and differences in elevation between the stations and the landslides are given in Table 2. The climatological data was obtained from published reports of the National Oceanic and Atmospheric Administration (U.S. Dept. of Commerce, 19771996). Unpublished compilations of the raw climatological data and information on the location and elevation of weather observing sites were obtained from the Colorado Climate Center, Fort Collins, Colorado. 


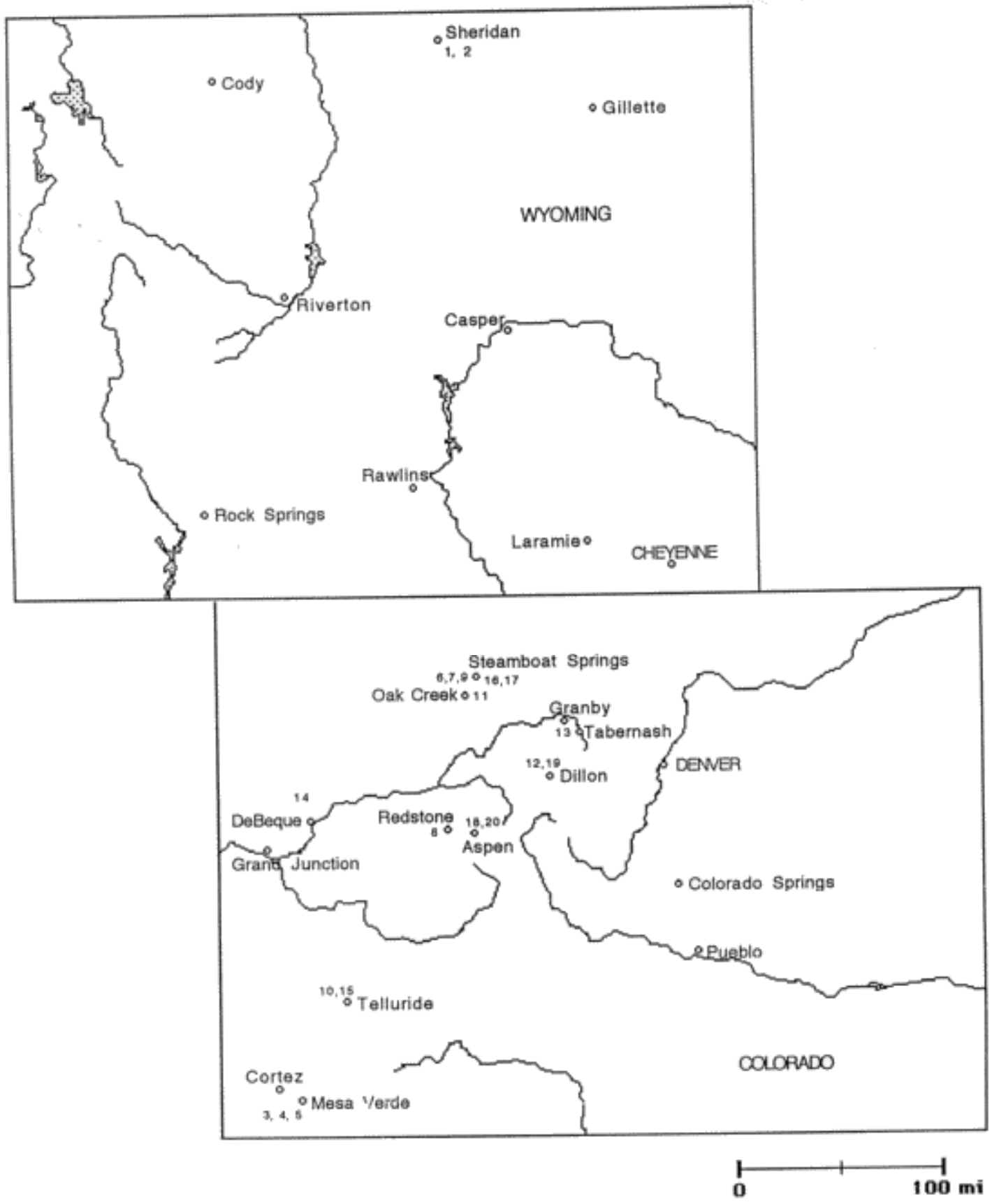

Figure 1.--Index map of Colorado and Wyoming showing the locations of landslides included in the study. Numbers shown are those of landslide events listed in Table 1.

\section{REPRESENTATIVENESS OF THE CLIMATIC DATA}

The following discussion is based on a recent study of climatic data representativeness in western Colorado by Doesken and others (1990). The study was conducted for the Bureau of Land 
Management to evaluate to what extent weather stations provide representative climatic information for surrounding unmonitored areas. In the study, monthly and seasonal climate variability were described. It was found that precipitation is much more variable than temperature, and that the range of representativeness of local weather station data to surrounding areas is much less for precipitation than for temperature. Also, Doesken and others (1990) showed that there is a good relationship of mean monthly maximum temperatures with elevation. It is stated that during the summer the relationship is so good that you can typically determine the mean monthly maximum temperature to within $+/-1$ degree Fahrenheit simply by knowing the elevation. Elevation, however, is only a secondary control on minimum temperature, especially during the winter months. Relative cold air trapping and draining characteristics of a given site become the primary control on night time temperatures. A correlation analyses of mean growing season (May-September) temperatures vs. elevation indicated a decrease of $4.5^{\circ} \mathrm{F}$ per $1000 \mathrm{ft}$ of elevation (r-squared $=0.95$ ). Also, correlation patterns developed in the study suggest areas in the same valley, regardless of their distance apart, are more likely to be well correlated than sites on the opposite sides of a mountain barrier. Likewise, stations far apart but with similar aspect relative to local terrain, may be better correlated. The Doesken and others (1990) study did not address climatic data representativeness on time scales shorter than a month. It is stated in the report that, in general, variability is increased with shorter sampling periods as you go down in time from monthly or seasonally to daily or weekly. And, for the shorter sampling periods, time series analyses, comparisons and correlations must be performed to attempt to determine representativeness.

For the purpose of estimating historical daily maximum and minimum temperatures at the landslide sites, I have assumed that the reported relationship between temperature and elevation $\left(-4.5^{\circ}\right.$ $\mathrm{F} / 1000 \mathrm{ft}$ elevation) is valid for a shorter sampling period. This assumption is based on the proximity of the weather stations to the 
respective landslide sites, and the apparent absence of significant, intervening terrain factors, such as major mountain divides. Because the range of representativeness is much less for precipitation than for temperature, I have made no attempt to make quantified estimates of historical daily precipitation for the landslide sites.

\section{DATA ANALYSIS and RESULTS}

As a first step, I corrected the raw daily temperature data for elevation differences between the weather stations and landslide sites using the relationship of Doesken and others (1990). Subsequent inspection of the corrected daily temperature data revealed that most of the landslide events were preceded by, or closely associated with, conspicuous 5- to 10-day intervals of rapidly rising temperatures wherein daily maximum temperatures typically rose from the 30's or 40's to the 60's or 70's. The mean length of the 5- to 10-day intervals was determined to be 6 days. In order to examine relationships between dates of landslide occurrence and antecedent temperature trends, I computed 6-day moving averages of daily maximum and minimum temperatures for the parts of each calendar year preceding the occurrence of each landslide event. To show antecedent temperature (snowmelt) conditions for specific dates, I then plotted the 6-day moving averages vs. calendar dates as line graphs with the moving average data points coinciding with the last day (calendar date) of the respective 6day intervals. Graphs for the periods of time that show the association between intervals of rising temperatures and dates of landslide events are presented in the appendix (figs. 2-19) As shown in Figures. 2-19, the landslide events are preceded by, or are coincidental with, conspicuous intervals of rising temperatures wherein the 6-day moving averages of daily maximum temperature reach into the high 50's or higher. Also note that, in general, the 6day moving average of daily minimum temperature is less variable than that of the daily maximum temperature. 
In a preliminary effort to identify a threshold temperature that might be used to forecast the onset of snowmelt related landsliding, I developed graphs showing the association between the dates of the landslide events and the first yearly occurrence of specific 6-day moving average temperatures. For this purpose, 6day moving averages of daily maximum temperatures in the range $50^{\circ}$ to $70^{\circ} \mathrm{F}$ were used. The following two measures were used in the attempt to identify the 6-day moving average of daily maximum temperature that would be most useful for forecasting purposes: (1) the total number of landslide events that occurred within 3 weeks after the first yearly occurrence of the potential threshold temperature, and (2) the degree of data clustering near the potential threshold temperature; defined as the sum of the differences between the landslide event dates and the date of the first yearly occurrence of the potential threshold temperature, in days. The potential threshold temperature with the highest number of landslide events, determined by the first measure, and the lowest sum of differences, determined by the second measure, would then be selected for forecasting purposes. Based on these criteria, I selected a 6-day moving average of $58^{\circ} \mathrm{F}$ as the proposed threshold temperature. However, when the measures were applied only minor differences between the $58^{\circ} \mathrm{F}$ average temperature and others in the 55 to $60^{\circ} \mathrm{F}$ range were apparent, suggesting that more sophisticated statistical measures and additional data are needed to refine the estimate. Because landslide events No. 1 and 2 were not complete landslide failures they were not included in the selection process. Landslide events No. 3 and 6 were included by assuming a midrange date of occurrence from within the bracketed range. Figure 20 shows the dates of the landslide events in relation to the first yearly occurrence of a 6-day average greater than or equal to $58^{\circ} \mathrm{F}$. As shown, most of the landslide events occurred within two weeks after the first yearly occurrence of the indicated $58^{\circ}$ threshold. The one event that definitely occurred before the $58^{\circ} \mathrm{F}$ threshold was reached (Landslide event No. 16, fig. 15) was 
preceded by a gradual warming trend that culminated in a 6-day moving average of $57^{\circ} \mathrm{F}$ on the day of the landslide event.

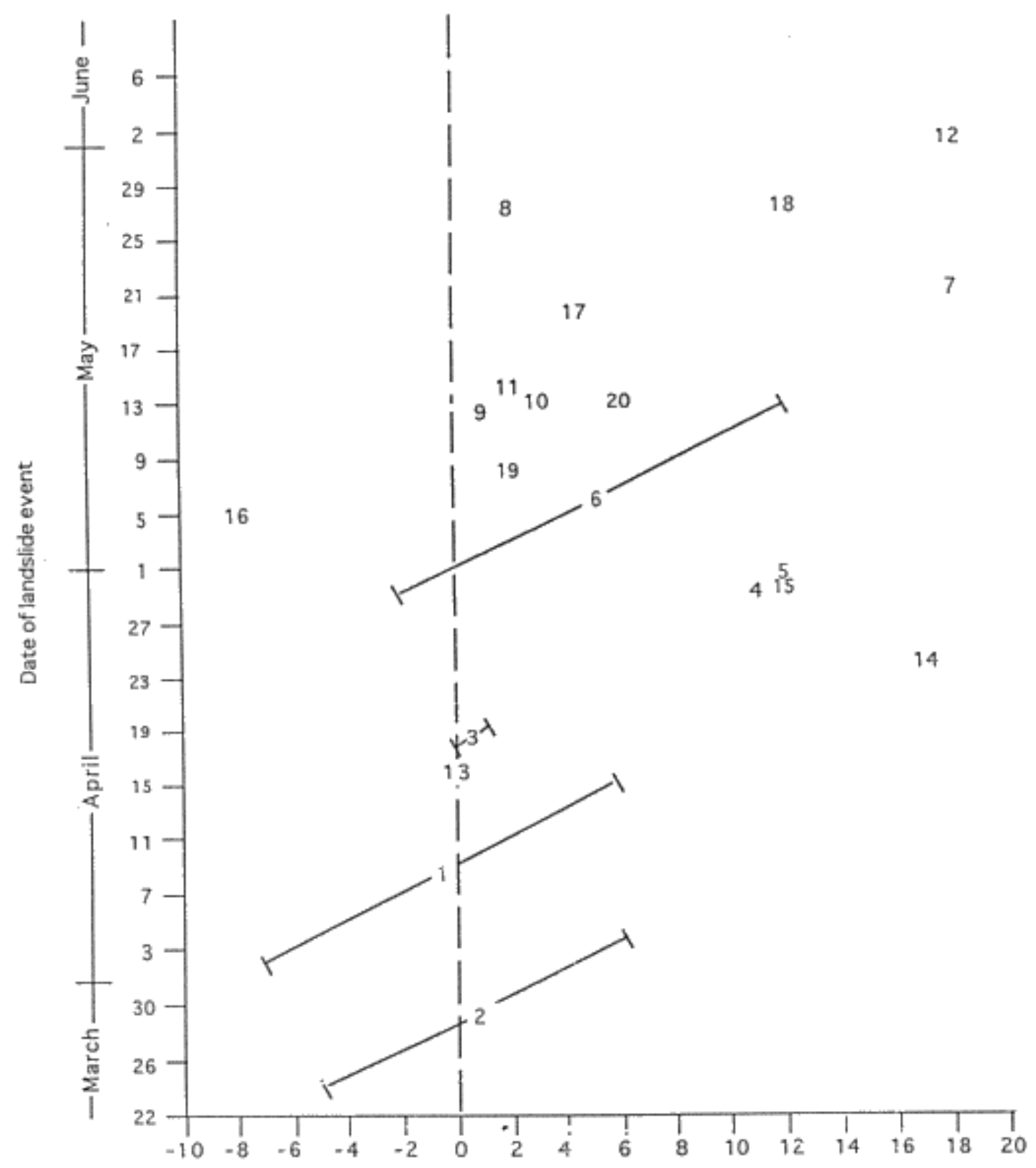

Number of days before or after first yearly occurrence of a 6 -day moving average $\geq 58^{\circ} \mathrm{F}$

Figure 20.-Plot showing dates of landslide events in relation to the first yearly occurrence of a 6-day moving average of daily maximum temperature greater than or equal to $58^{\circ} \mathrm{F}$. Plotted numbers are landslide events identified in Table 1 and Figures 2-19. Note that a high percentage of the landslide events occurred within 18 days after the first yearly occurrence of the proposed $58^{\circ} \mathrm{F}$ threshold. 
Because elevation is only a secondary control on minimum temperatures and minimum temperatures are less variable than maximums, I did not attempt to develop graphs similar to that of Figure 20 for the daily minimums. It seems reasonable to expect a close association between the onset of snowmelt related landslides and the first yearly occurrence of sustained daily minimum temperatures above freezing $\left(32^{\circ} \mathrm{F}\right)$. However, visual examination of the plots (figs. 2-19) indicate that, although there appears to be an association, only about half of the 20 landslide events preceded the first yearly occurrence of a 6-day moving average greater than or equal to $32^{\circ} \mathrm{F}$; therefore, it would not be as useful for forecasting the onset of spring season landslides as the 6-day daily maximum average of $58^{\circ} \mathrm{F}$.

As previously stated, I have assumed that the reported relationship between temperature and elevation $\left(-4.5^{\circ} \mathrm{F} / 1000 \mathrm{ft}\right.$ of elevation increase) is valid for the 6-day sampling periods. A study of temperature representativeness for the relatively short distances considered in this study is beyond the scope of this report. However, the few comparisons I have made of daily temperature data recorded at weather stations separated by similar distances suggests a good correlation. An example is the 6-day moving averages of daily maximum temperature from the Sheridan AP weather station (fig. 2) and that for the same March 6 to April 30, 1977 period from a weather station located $7 \mathrm{mi}$ to the northeast (Sheridan Field Station). Comparison of the data (corrected for an elevation difference of $240 \mathrm{ft}$ ) is shown in Figure 21. 

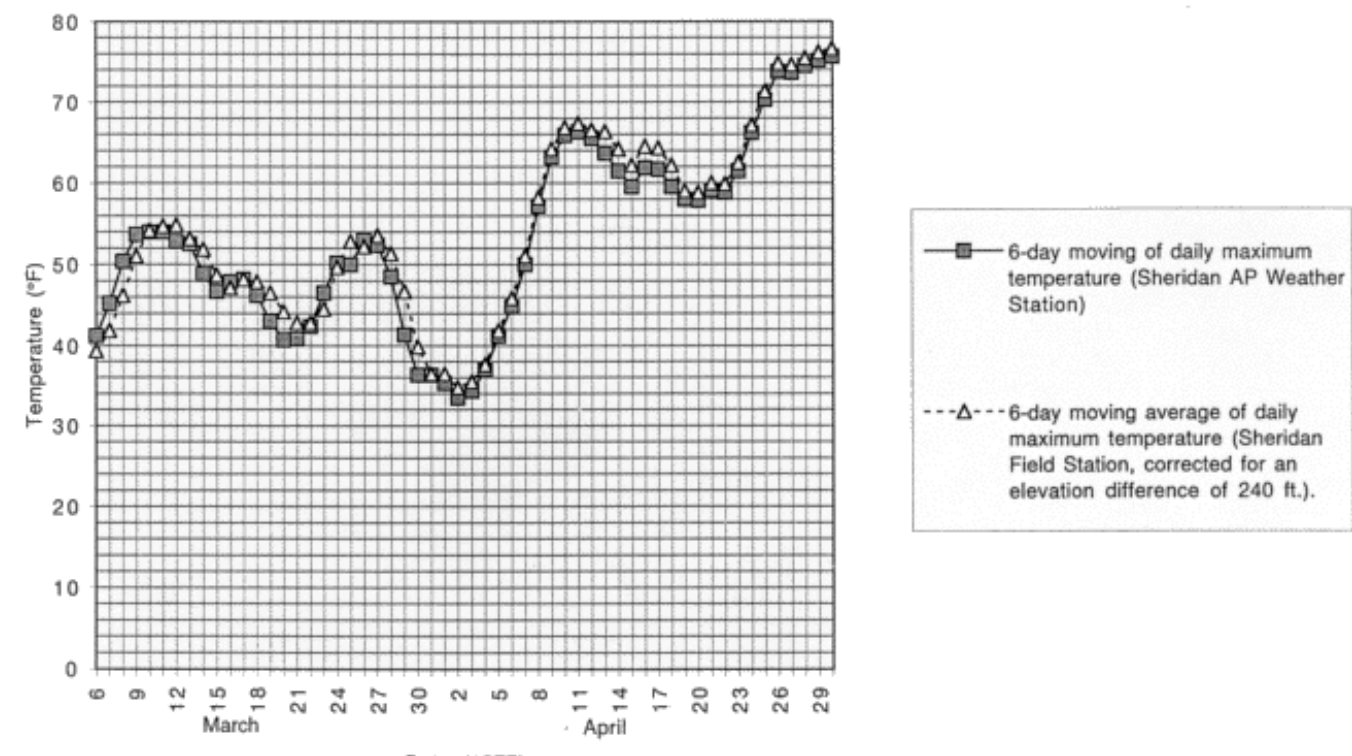

Figure 21. Comparison of 6-day moving averages of daily maximum temperatures recorded at Sheridan AP and Sheridan Field Station weather stations during the period March 6, to April 30, 1977.

\section{DISCUSSION AND CONCLUSIONS}

The results of this preliminary study suggest that temperature data recorded at weather stations throughout the Rocky Mountain region is potentially a valuable source of information for forecasting the onset of spring season landslides. Beginning in March of each year, moving averages of real-time daily temperatures obtained from local weather stations could be used to pinpoint the first occurrences of the threshold temperature in the respective areas of interest. Forecasts could then be issued to the media and appropriate government agencies warning of the increased potential for landsliding. In addition to insuring public awareness, the forecasts could be used for such things as planning and scheduling highway maintenance, timing the deployment of field instrumentation, and monitoring potentially hazardous landslide masses.

Although the combination of deep snowpack and warming trends sufficient to cause significant snowmelt usually occur in the spring of each year in the central Rocky Mountains, it can occasionally 
occur at other times of the year as well. It follows that the first yearly occurrence of the threshold temperature may, on occasion, arrive before the spring season. Also, areas outside of the area of this study that have significantly different regional climates have experienced widespread landsliding involving snowmelt with rainon-snow storms during the winter months (e.g., Day and Megahan, 1976). Temperatures and temperature trends associated with those events may differ significantly from those of this study. This study is based on a limited number of spring season landslide events and only minimal amounts of information on the various geologic, hydrologic, and climatic factors that may have contributed to their occurrence. Additional work is needed to expand the landslide database and further evaluate the representativeness of the temperature data. Such work would likely result in refinement of the threshold value and an improved forecasting capability.

\section{REFERENCES}

Aspen Daily News, 1993, Reconnected again; the Pass opens early: Aspen, Colorado, May 28, p. 1 and 6.

Aspen Times, 1983, Redstone mud scare causes evacuation of valley residents: Aspen, Colorado, June 2, p. 10.

Chleborad, Alan F., 1980, Investigation of a natural slope failure in weathered Tertiary deposits, western Powder River Basin, Wyoming: U.S. Geological Survey Open-File Report 80-673, 66 p. Day, N.F., and Megahan, W.F., 1976, Landslide occurrence on mountainous terrain in north central Idaho: A progress report, 1974-75: Proceedings of the 14th Annual Symposium of Engineering Geologists and Soils Engineeers, Boise State University, April 7,8, and 9th, p. 85-104. 
Doesken, Nolan J., McKee, Thomas B., and Kleist, John, 1990, Climatic data representativeness in western Colorado: Colorado State University Climatology Report No. 90-1, 43 p.

Montezuma Valley Journal, 1979, Slides on Mesa Verde: Cortez, Colorado, April 20, p. 1.

Montezuma Valley Journal, 1979, Mesa Verde remains closed: Cortez, Colorado, May 2, p. 1.

Schuster, Robert L., 1986, Amtrak wreck caused by landslide near Granby, Colorado: Ground Failure, National Research Council Committee on Ground Failures, No. 3, Spring 1986.

Steamboat Pilot, 1982, Mud slides damage ski jumps: Steamboat Springs, Colorado, May 13,

p. 1.

Steamboat Pilot, 1982, See Me, see mudslide: Steamboat Springs, Colorado, May 27, p. 1.

Steamboat Pilot, 1984, Rising waters flood Route County:

Steamboat Springs, Colorado, May 17, p. 1.

Steamboat Pilot, 1993: Mud slides down runs at ski area:

Steamboat Springs, Colorado,

May 27, p. 1.

Stover, B.K., Cannon, S.H., and Junge, Rahe W., 1987, The April 30, 1987 Telluride Airport landslides and resultant debris flows:

Colorado Geological Survey Department of Natural Resources Open-File Report 87-2, 14 p.

Summit County Journal, 1984, Mudslide blocks Blue River: Dillon, Colorado, June 14, p. 3.

Telluride Times, 1984, Woman dies in mud slide; melting snow wrecks county roads: Telluride, Colorado, May 17, p.1.

Umstot, David, 1989, Field studies and modeling analysis of the Roan Creek landslide, Garfield County, Colorado: Colorado Geological Survey Department of Natural Resources Open File Report 89-1, 67 p.

U.S. Department of Commerce, 1977, Wyoming climatological data: Daily temperature data, 
v. 86, No.s 1-4.

U.S. Department of Commerce, 1978, Wyoming climatological data: Daily temperature data, v. 87, No.s 1-4.

U.S. Department of Commerce, 1979, Colorado Climatological Data: Daily temperature data, v. 84, No.s 1-5.

U.S. Department of Commerce, 1982, Colorado Climatological Data: Daily temperature data, v. 87, No.s 1-5.

U.S. Department of Commerce, 1984, Colorado Climatological Data: Daily temperature data, v. 89, No.s 1-5.

U.S. Department of Commerce, 1985, Colorado Climatological Data: Daily temperature data, v. 90, No.s 1-4.

U.S. Department of Commerce, 1987, Colorado Climatological Data: Daily temperature data, v. 92, No.s 1-5.

U.S. Department of Commerce, 1993, Colorado Climatological Data: Daily temperature data, v. 98, No.s 1-5.

U.S. Department of Commerce, 1996, Colorado Climatological Data: Daily temperature data, v. 101, No.s 1-5

\section{APPENDIX}

\section{(Figures 1-21)}

Figures for U.S. Geological Survey Open-File Report 97-27 
* $\quad$ Figure 1.--Index map of Colorado and Wyoming showing the locations of landslides included in the study. Numbers shown are those of landslide events listed in Table 1.

* $\quad$ Figure 2.--Graph showing the association of landslide event No. 1 with rising temperatures and the first yearly occurrence of a 6-day moving average of daily maximum temperature greater than or equal to $58^{\circ} \mathrm{F}$.

* $\quad$ Figure 3.--Graph showing the association of landslide event No. 2 with rising temperatures and the first yearly occurrence of a 6-day moving average of daily maximum temperature greater than or equal to $58^{\circ} \mathrm{F}$.

* $\quad$ Figure 4.--Graph showing the association of landslide events No. 3, 4, and 5 with rising temperatures and the first yearly occurrence of a 6-day moving average of daily maximum temperature greater than or equal to $58^{\circ} \mathrm{F}$.

* $\quad$ Figure 5.--Graph showing the association of landslide event No. 6 with rising temperatures and the first yearly occurrence of a 6-day moving average of daily maximum temperature greater than or equal to $58^{\circ} \mathrm{F}$.

* $\quad$ Figure 6.--Graph showing the association of landslide event No. 7 with rising temperatures and the first yearly occurrence of a 6-day moving average of daily maximum temperature greater than or equal to $58^{\circ} \mathrm{F}$.

* $\quad$ Figure 7.--Graph showing the association of landslide event No. 8 with rising temperatures and the first yearly occurrence of a 6-day moving average of daily maximum temperature greater than or equal to $58^{\circ} \mathrm{F}$.

* $\quad$ Figure 8.--Graph showing the association of landslide event No. 9 with rising temperatures and the first yearly occurrence of a 6-day moving average of daily maximum temperature greater than or equal to $58^{\circ} \mathrm{F}$.

* $\quad$ Figure 9.--Graph showing the association of landslide event No. 10 with rising temperatures and the first yearly occurrence of a 6-day moving average of daily maximum temperature greater than or equal to $58^{\circ} \mathrm{F}$. 
* $\quad$ Figure 10.--Graph showing the association of landslide event No. 11 with rising temperatures and the first yearly occurrence of a 6-day moving average of daily maximum temperature greater than or equal to $58^{\circ} \mathrm{F}$.

* $\quad$ Figure 11.--Graph showing the association of landslide event No. 12 with rising temperatures and the first yearly occurrence of a 6-day moving average of daily maximum temperature greater than or equal to $58^{\circ} \mathrm{F}$.

* $\quad$ Figure 12.--Graph showing the association of landslide event No. 13 with rising temperatures and the first yearly occurrence of a 6-day moving average of daily maximum temperature greater than or equal to $58^{\circ} \mathrm{F}$.

* $\quad$ Figure 13.--Graph showing the association of landslide event No. 14 with an antecedent interval of rising temperatures and the first yearly occurrence of a 6-day moving average of daily maximum temperature greater than or equal to $58^{\circ} \mathrm{F}$.

* $\quad$ Figure 14.--Graph showing the association of landslide event No. 15 with rising temperatures and the first yearly occurrence of a 6-day moving average of daily maximum temperature greater than or equal to $58^{\circ} \mathrm{F}$.

* $\quad$ Figure 15.--Graph showing the association of landslide event No. 16 with rising temperatures and the first yearly occurrence of a 6-day moving average of daily maximum temperature greater than or equal to $58^{\circ} \mathrm{F}$.

* $\quad$ Figure 16.--Graph showing the association of landslide event No. 17 with rising temperatures and the first yearly occurrence of a 6-day moving average of daily maximum temperature greater than or equal to $58^{\circ} \mathrm{F}$.

* $\quad$ Figure 17.--Graph showing the association of landslide event No. 18 with rising temperatures and the first yearly occurrence of a 6-day moving average of daily maximum temperature greater than or equal to $58^{\circ} \mathrm{F}$.

* $\quad$ Figure 18.--Graph showing the association of landslide event No. 19 with rising temperatures and the first yearly occurrence of a 
6-day moving average of daily maximum temperature greater than or equal to $58^{\circ} \mathrm{F}$.

* $\quad$ Figure 19.--Graph showing the association of landslide event No. 20 with rising temperatures and the first yearly occurrence of a 6-day moving average of daily maximum temperature greater than or equal to $58^{\circ} \mathrm{F}$.

* $\quad$ Figure 20.--Plot showing dates of landslide events in relation to the first yearly occurrence of a 6-day moving average of daily maximum temperature greater than or equal to $58^{\circ} \mathrm{F}$. Plotted numbers are landslide events identified in Table 1 and Figures 219. Note that a high percentage of the landslide events occurred within 18 days of the first yearly occurrence of the proposed $58^{\circ} \mathrm{F}$ threshold.

* $\quad$ Figure 21.--Comparison of 6-day moving averages of daily maximum temperatures recorded at Sheridan AP and Sheridan Field Station weather stations during the period March 6 to April 30, 1977.

\section{Alan F. Chleborad}

$\begin{array}{ll}* & \text { U.S. Geological Survey } \\ * & \text { Geologic Hazards team } \\ * & \text { Landslide Hazards Group } \\ * & \text { email: chleb@gldvxa.cr.usgs.gov } \\ * & \text { P.O. Box 25046, MS 966 } \\ * & \text { Lakewood, CO 80225 }\end{array}$

